\title{
Microstructure of $\mathrm{Ba}_{0.615} \mathrm{Sr}_{0.35} \mathrm{Mg}_{0.035} \mathrm{TiO}_{3}$ dielectric ceramics via $\mathrm{X}$-ray spectrum analysis
}

\author{
QI Wen ${ }^{1 \dagger}$, XUE Tao $^{1,2 \dagger}$, LI Xuan $^{2}$, FANG DongYu ${ }^{1}$, LI ChaoLing $^{1} \&$ YAO Pei ${ }^{1,2^{*}}$ \\ ${ }^{1}$ School of Materials Science and Engineering, Tianjin University, Tianjin 300072, China; \\ ${ }^{2}$ Center for Analysis, Tianjin University, Tianjin 300072, China
}

Received May 24, 2012; accepted September 5, 2012

\begin{abstract}
The compound $\mathrm{Ba}_{0.615} \mathrm{Sr}_{0.35} \mathrm{Mg}_{0.035} \mathrm{TiO}_{3}$ was analyzed by the X-ray dispersed spectroscopy analyzer (SEM-EDAX) with the spectrum image method, a powerful tool for chemical phase identification. The method was first time applied on a ceramic material to collect spectrum image and was progressed to identify the Mg-enriched component with fine scale pocket shown in matrix. This result, together with the stoichiometry result obtained from spot mode spectrum analysis, strongly confirmed the microstructure and properties of dielectric materials.
\end{abstract}

microstructure, dielectric ceramics, $X$-ray analysis, spectrum imaging

Citation: Qi W, Xue T, Li X, et al. Microstructure of $\mathrm{Ba}_{0.615} \mathrm{Sr}_{0.35} \mathrm{Mg}_{0.035} \mathrm{TiO}_{3}$ dielectric ceramics via X-ray spectrum analysis. Chin Sci Bull, 2012, 57: 4510-4512, doi: $10.1007 / \mathrm{s} 11434-012-5517-0$

Barium strontium titanate (BST) materials have shown the great potential for dielectric applications because of their high tenability and low dielectric losses [1]. In the BST system, the additive of $\mathrm{MgO}$ or $\mathrm{Mg}$ doping in BST ceramics will change the perovskite $\mathrm{ABO}_{3}$ structure of $\mathrm{BST}$, which leads to the significant suppression of permittivity and losses [2,3]. However, the solubility limit of $\mathrm{Mg}$ content in the BST ceramics will affect the microstructure and dielectric properties of BST ceramics $[2,4,5]$. Because of the low levels of the additives, it is necessary to directly detect the distribution of complex components in the materials.

Energy dispersive X-ray spectrum (EDS) mapping, in which the complete X-ray spectrum is collected at every pixel in the sample, is a new and powerful tool for materials characterization [6-9]. Spectrum mapping is different from the conventional element mapping (regions of interest mapping, ROI mapping), in which only windows around preselected energy ranges are acquired and only the chosen elements are showed. In the spectrum mapping method, the

$†$ These authors contributed equally to this work

*Corresponding author (email: pyao@tju.edu.cn) entire spectrum information is collected at each pixel in spectrum mapping as the beam is rastered across the specimen [7]. This technology allows even unexpected elemental features to be detected after data has been collected. Additionally, the elemental distribution and a corresponding image describing the distribution for each chemical component in the microstructure are offered with this new analysis tool [9]. The new class of energy dispersive X-ray spectrometer, the silicon drift detector (SDD) with less accumulation time and better energy resolution $[6,10,11]$ than the conventional $\mathrm{Si}$-EDS, make it possible to get the compositional nature of the materials with the spectrum imaging analysis.

Although some studies on the diffusion of components of alloy $[12,13]$ and the chemical phases segregation near the interface in the metal-ceramic braze [14] by X-ray spectrum analysis, the composition and phase distribution of compound ceramics are not statistically analyzed with this new and efficient spectrum image analysis. In this paper, the microstructure of $\mathrm{Ba}_{0.615} \mathrm{Sr}_{0.35} \mathrm{Mg}_{0.035} \mathrm{TiO}_{3}$ ceramics is studied with $\mathrm{X}$-ray spectrum mapping techniques, which are used to describe the chemical composition and distribution of the phase in $\mathrm{Mg}$ doping BST dielectric ceramics. 


\section{Materials and methods}

$\mathrm{Ba}_{0.65-x} \mathrm{Sr}_{0.35} \mathrm{Mg}_{x} \mathrm{TiO}_{3}$ ceramics were prepared by solid oxide reaction. Stoichiometric titanium oxide $(98 \%)$, barium carbonate $(99 \%)$ and strontium carbonate $(99 \%)$ powders were used as raw materials. $\mathrm{Mg}$ doping was introduced from magnesium hexahydrate $(99 \%)$ with molar percentages of $0.035(3.5 \mathrm{~mol} \%)$. The mixtures were ball-milled, dried and calcined at $1080^{\circ} \mathrm{C}$ for $2 \mathrm{~h}$ to get the BST powders. The calcined powders were mixed with 0.2 at $\%$ zirconium oxide and 0.2 at $\%$ manganese dioxide, following ball milled for $24 \mathrm{~h}$ with polyvinyl alcohol as a solvent. Dried powders were pressed into disks $(10.00 \mathrm{~mm} \times 2.00 \mathrm{~mm})$ at $250 \mathrm{MPa}$ and sintered at $1290^{\circ} \mathrm{C}$ for $2 \mathrm{~h}$. After calcination, the BST ceramics specimen was coated with thin carbon layer for further X-ray analysis. The spectrum mapping was performed in SEM (Nano2000, FEI) operated at $20 \mathrm{kV}$, acquired with a silicon drift detector (SDD) in EDAX. The X-ray spectrum images of $266 \times 200$ pixels were recorded with 1000 channels per spectrum (10 eV channel). The pixel dwell time was chosen according to the nature of the experiment. The beam energy of $20 \mathrm{keV}$ was used for all measurements. The beam current was adjusted to produce an output count rate of 220000 counts/s. The EDAX Genesis Drift Correction was used to track the drift of specimen during the maps collection. Phase Cluster Analysis was performed with EDAX Genesis software after all the data was collected.

\section{Results and discussion}

To investigate the microstructure of the BST ceramics, the X-ray analyses with different analytical methods were used. A scanning electron micrograph of a typical cross section of BST ceramics with $3.5 \mathrm{~mol} \% \mathrm{Mg}$ doping was presented in Figure 1(a). The corresponding conventional elements maps (ROI maps) represented for the distribution of $\mathrm{Mg}, \mathrm{Ba}$ and Ti elements had been acquired (Figure 1(b)-(d)). ROI maps indicated the diffusion of $\mathrm{Mg}$ (green) and the absence of $\mathrm{Ba}$ (red) and $\mathrm{Ti}$ (blue) in the same area. In microstructures of BST ceramics containing five elements with a potentially complex distribution, it is necessary to identify not just the elements present but the chemical phases and their distribution, as phase mapping assumes knowledge of atomic positions and required diffraction analysis [7]. The phase cluster analysis method based on a spectrum image is required to get the chemical phase distribution in the microstructures.

The spectrum image was acquired with a SDD for a BST sample doped with $3.5 \mathrm{~mol} \% \mathrm{Mg}$. The spectrum image data had been further processed with Phase Cluster Analysis software, which automatically found phases in the recorded data by clustering spectra at each pixel based on statistical similarity of spectra. Through the phase cluster analysis, the mapping of chemical phase was possible through selecting the clusters and then displaying the similar concentration
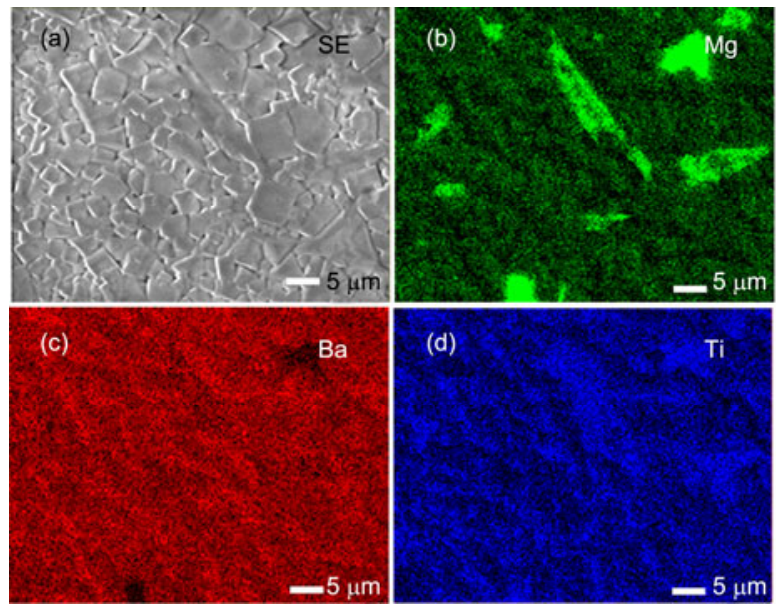

(d)

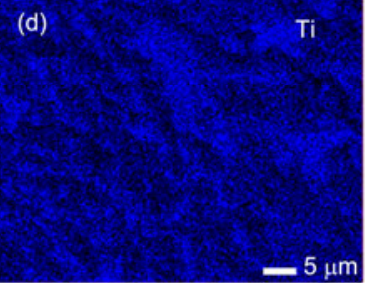

Figure 1 (a) SEM image of the analyzed region of the specimen; (b)-(d) corresponding ROI maps of $\mathrm{Mg} \mathrm{K} \alpha, \mathrm{Ba} \mathrm{K} \alpha$ and $\mathrm{Ti} \mathrm{K} \alpha$; $\mathrm{Mg}=$ green, $\mathrm{Ba}=$ red, $\mathrm{Ti}=$ blue.

areas on the image. The chemical phases identified by phase cluster analysis consisted of component image/spectrum pairs, which could indicate more information not only the elements distribution but the chemical phase mapping.

The Chi-square statistic fit that is typically employed as a goodness of fit metric for iterative fitting of reflectivity spectrum in Phase Cluster Analysis software [15] was used to identify the chemical phase and the coverage of phase in the image. The phase cluster analysis indicated that there were three components in the spectrum image, where the red, green, blue colors were assigned for each pixel based on the closest found phase (Figure 2(b)). Figure 2(b) and (c) were the component images and the corresponding summation statistical spectrums from the $(\mathrm{Mg}, \mathrm{Ba}, \mathrm{Ti}, \mathrm{Sr}, \mathrm{O}) \mathrm{com}-$ pounds. Three distinct statistical spectrums with the same elements but different elements ratio of component could be
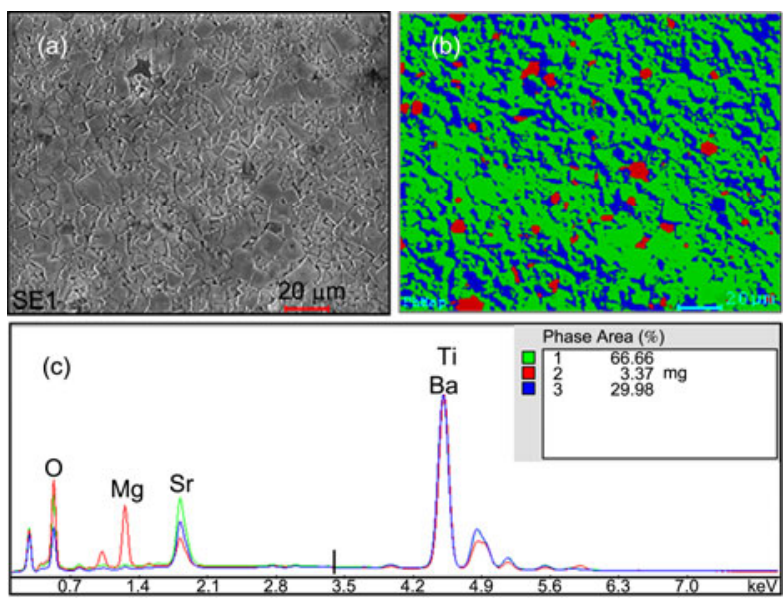

Figure 2 (a) SEM image of the analyzed region of the specimen; (b) composite image from the chemical cluster phase analysis showing the identification of Mg-enriched component (red) concentrated in a small pocket, as well as at low levels on the grain boundary; (c) corresponding sum X-ray spectrums. Insert is the coverage of each chemical phase in the analyzed region of the specimen. 
recognized in the images. As shown in Figure 2(c), the spectrum with green color and the one with blue are similar in the contents of elements, just a little variation of strontium and oxygen contents $(9.39$ at $\% \mathrm{Sr}$ in the green one, 7.39 at\% $\mathrm{Sr}$ in the blue one). The atomic ratio of elements in these two spectrums was calculated and was consistent with the desired ratio of Mg doped BST ceramics [2,3,5], which can be assumed as the chemical phase of matrix. However, the spectrum presented as red color showed the apparently high $\mathrm{Mg}$ content compared to the matrix (16 at $\%$ vs. 1 at $\%$ ). The phase images and spectrums revealed the homogeneous components presented in the Mg doped BST ceramics matrix. It was also presented in pockets with Mg-rich component, with $3 \%$ coverage of phase area, randomly in the matrix. In addition to the phase identification, the spectrum image analysis showed the fine scale Mg-rich component with the scale of $5-10 \mu \mathrm{m}$ was precipitated in the grain boundary that would be otherwise missed. Thus, the phase cluster analysis provided direct evidence of discrete the fine precipitates enriched in $\mathrm{Mg}$ distributed within the matrix.

Further quantitative analysis with spot mode EDS provided a measurement of the matrix composition and the precipitation in the grain boundary. It was convinced the stoichiometry of matrix and the Mg-rich phase in specific location identified by the phase cluster analysis below. The matrix stoichiometry was very similar to a compound that had been desired as $\mathrm{Ba}_{0.615} \mathrm{Sr}_{0.35} \mathrm{Mg}_{0.035} \mathrm{TiO}_{3}$ (Table 1). The $\mathrm{Mg}$-rich phase was also confirmed and the stoichiometry was listed in the dialog, which indicated the $\mathrm{Mg}$ concentration and precipitation in the matrix, consistent with the result determined by Phase Cluster Analysis.

Our previous systematic study on the dielectric properties with $\mathrm{Mg}$ doping levels from 0 to $3.5 \mathrm{~mol} \%$ in BST ceramics investigated the effect of different $\mathrm{Mg}$ content on the lattice parameter and dielectric properties [5]. The permittivity decreases with the $\mathrm{Mg}$ concentration and the dissipation remains constant. In this paper, the directly mapped segregation of $\mathrm{Mg}^{2+}$ and fine scale precipitation are the strong contribution to the abnormal dielectric losses of $3.5 \mathrm{~mol} \%$ Mg doping BST ceramics, as in the previous work. The microstructure analysis reveals $3 \mathrm{~mol} \%$ is the solubility limit of $\mathrm{Mg}$ in the BST ceramics. Similar high content of $\mathrm{Mg}$ induced segregation of Mg-rich component on the grain boundaries has been reported in other nanoceramic composites (e.g. SiC/alumina) [16].

\section{Conclusions}

$\mathrm{X}$-ray spectrum imaging combined with phase cluster analysis software is a powerful technique for extending the capabilities of EDS analysis for comprehensive area analysis, which has been successfully applied to the characterization of
Table 1 The component of Mg-BST ceramics analyzed by spot mode EDS

\begin{tabular}{lccccc}
\hline \multicolumn{1}{c}{ Phase } & $\mathrm{Ba}(\mathrm{at} \%)$ & $\mathrm{Ti}(\mathrm{at} \%)$ & $\mathrm{Sr}(\mathrm{at} \%)$ & $\mathrm{O}(\mathrm{at} \%)$ & $\mathrm{Mg}(\mathrm{at} \%)$ \\
\hline Matrix & 15.64 & 25.65 & 9.29 & 49.09 & 1.02 \\
Precipitation & 2.75 & 23.99 & 1.42 & 55.63 & 16.22 \\
\hline
\end{tabular}

compound BST ceramics. The chemistry and distribution of phases were identified in the microstructure of $\mathrm{Mg}$ doped BST ceramics. It has enabled detection and analysis of fine scale $\mathrm{Mg}$ precipitated in the grain boundary when the $\mathrm{Mg}$ additive is higher than the desired solubility, which would be lost by other techniques such as ROI mapping. The interfacial microstructure analysis suggests that the $\mathrm{Mg}$ dopant should be lower than $3.5 \mathrm{~mol} \%$ to avoid the segregation.

This work was performed at the Analysis Center of Tianjin University, a multi-program department operated by Tianjin University. Wen Qi would like to express thanks to Dr. Shiguo Xu, the Department of Materials Science and Engineering of Tianjin University, for his contributions of samples and discussions.

1 Gevorgian S S, Kollberg E L. Do we really need ferroelectrics in paraelectric phase only in electrically controlled microwave devices? IEEE Trans Microw Theor Tech, 2001, 49: 2117-2124

2 Su B, Button T W. Microstructure and dielectric properties of Mg-doped barium strontium titanate ceramics. J Appl Phys, 2004, 95: 1382-1385

3 Cole M W, Joshi P C, Ervin M H, et al. The influence of Mg doping on the materials properties of $\mathrm{Ba}_{1-x} \mathrm{Sr}_{x} \mathrm{TiO}_{3}$ thin films for tunable device applications. Thin Solid Films, 2000, 374: 34-41

4 Cole M W, Hubbard C, Ngo E, et al. Structure-property relationships in pure and acceptor-doped $\mathrm{Ba}_{1-x} \mathrm{Sr}_{\mathrm{x}} \mathrm{TiO}_{3}$ thin films for tunable microwave device applications. J Appl Phys, 2002, 92: 475-483

$5 \mathrm{Xu} \mathrm{S}, \mathrm{Qu} \mathrm{Y}$, Zhang C. Effect of $\mathrm{Mg}^{2+}$ content on the dielectric properties of $\mathrm{Ba}_{0.65-x} \mathrm{Sr}_{0.35} \mathrm{Mg}_{x} \mathrm{TiO}_{3}$ ceramics. J Appl Phys, 2009, 106: 014107

6 Newbury D E. The new X-ray mapping: X-ray spectrum imaging above $100 \mathrm{kHz}$ output count rate with the silicon drift detector. Microsc Microanal, 2006, 12: 26-35

7 Wuhrer R, Moran K, Moran L. Characterisation of materials through X-ray mapping. Mater Sci Forum, 2006, 3: 63-70

8 Ritchie N W M. Spectrum simulation in DTSA-II. Microsc Microanal, 2009, 15: 454-468

9 Newbury D E, Ritchie N W M. Can X-ray spectrum imaging replace backscattered electrons for compositional contrast in the scanning electron microscope? Scanning, 2011, 33: 174-192

10 Newbury D, Davis J, Bright D, et al. Compositional mapping by $\mathrm{X}$-ray spectrum imaging at $1 \mathrm{MHz}$ output count rate with the silicon drift detector. Microsc Microanal, 2008, 14: 1164-1165

11 Newbury D E. The new X-ray mapping: Applying the silicon drift detector (SDD) for X-ray spectrometry and spectrum imaging with output count rates above $100 \mathrm{kHz}$. Microsc Microanal, 2005, 11: 1328-1329

12 Loehman R E, Kotula P G. Spectral imaging analysis of interfacial reactions and microstructures in brazing of alumina by a $\mathrm{Hf}-\mathrm{Ag}-\mathrm{Cu}$ alloy. J Am Ceram Soc, 2004, 87: 55-59

13 Krestnikov N, Semenov A, Novozhilov S, et al. Structure of welds of corrosion-resistant steel and titanium alloy. Met Sci Heat Treat, 2009, 51: 194-197

14 Kotula P G, Keenan M R, Anderson I M. SEM/EDX spectrum imaging and statistical analysis of a metal/ceramic braze. MRS Proceedings, 2000, 589: 329

15 EDAX Inc. EDAX User's Manual, 2007

16 Sengupta L C, Sengupta S. Breakthrough advances in low loss, tunable dielectric materials. Mater Res Innov, 1999, 2: 278-282

Open Access This article is distributed under the terms of the Creative Commons Attribution License which permits any use, distribution, and reproduction in any medium, provided the original author(s) and source are credited. 